mathematics instruction." Prof. Franklin also raises certain objections to the syllabus definition of differentials, but we are sorry to see that he himself perpetuates the worst defects of our text-books by expanding series of powers of differentials. It is, of course, possible to expand $f(x+d x)-f(x)$ in powers of $d x$, and when the result is divided by $d x$ the limit of the series does happen to be equal to the differential coefficient in most cases, but the differential coefficient cannot be defined as the limit of the series in question. It would be equally legitimate to expand $f(x)-f(x-d x)$ or $f\left(x+\frac{1}{2} d x\right)-f\left(x-\frac{1}{2} d x\right)$. The notion of a differential coefficient depends essentially on the assumption that the ratio of $f\left(x_{2}\right)-f\left(x_{1}\right)$ to $x_{2}-x_{1}$ tends to a unique limit when $x_{2}$ and $x_{1}$ both tend to the same finite limit $x$. Further, we think it would be much better to follow Newton's example by defining equality of differentials instead of trying to define the differentials themselves. The student who is taught always to add $d x$ on to the end of $x$ fails to grasp the very foundation of the calculus. The failing cases may be exemplified by "density" at a point on the surface separating two media.

WE have pleasure in directing attention to the little volume entitled "Manchester in 1915," which has been issued (in Manchester by the University Press, and in London by Messrs. Longmans and Co.) at one shilling net, it being the handbook for the forthcoming meeting of the British Association. While less pretentious than many previous association handbooks, it is a noteworthy production, and one which should be of great service to those attending the meeting; it will doubtless also appeal to many residents in and adjacent to Manchester, for it contains some very readable and informing articles on institutions of, and matters pertaining to, the city; thus, a brief historical sketch is contributed by Prof. J. Tait; Prof. Tout deals with the University, Dr. Tattersall with the museum, Mr. H. Guppy with the John Rylands Library, and Prof. Hickson with the Literary and Philosophical Society. Mr. Spurley Hey has two articles on, respectively, elementary education in Manchester, and secondary schools in Manchester, and Mr. J. H. Reynolds deals with the evening-school system of Manchester. In addition to the foregoing, the volume is finely illustrated by some fourteen platesone in colour. Both text and illustrations are beautifully printed.

The Institute of Chemistry proposes to issue a special edition (limited to roo copies) of the history of the institute, $1877-1914$, and orders for it can now be received. Any profit arising out of its sale will be devoted to the building fund

Mr. W. H. Dines informs us that a mistake occurs in his letter in Nature of August 12 on "The Probable Error of the Amplitudes in a Fourier Series obtained from a Given Set of Observations." The passage in question should read:- "To obtain $p$ we write $n p / 2=y_{0} \sin o+y_{1} \sin \frac{2 \pi}{n}$. . . etc., instead of $p=y_{0} \sin 0 \ldots$

$$
\text { NO. 2392, VOL. 96] }
$$

OUR ASTRONOMICAL COLUMN.

Absolute Stellar Motions.-Meddelande No. 05 , from the Lunds Astronomical Observatory, gives an account of an important statistical study of the distribution of the absolute motions of a number of parallax stars which has been made by $\mathrm{Mr}$. K. W. Gyllenberg. After excluding parallaxes smaller than 0.015 ", there remain 160 stars for which absolute velocities can be determined. The components were calculated for an axis " $Z$ " pointed to the galactic pole, an " $\mathrm{H}$ " axis in the plane of the Milky Way, whilst the third " $\Xi$ " was directed towards the vertex found for I470 stars with known radial velocities. The numerical work was curtailed by using Prof. Charlier's plan of dividing the sky into forty-eight compartments, and using the co-ordinates of the centres for the contained stars. Prof. Charlier's units Siriometer ( $1 \mathrm{Sm}=10^{6}$ dist. earth-sun) and Stellar-year (1 St. $=10^{6}$ years) have been used (1 Sm/st. $=4.7375 \mathrm{~km} . / \mathrm{sec}$.). After arranging the material according to type of spectrum, five star types, KI (Arct.) to A2p (Cyg.), were excluded as having excessive velocities. The greatest mean velocities were found in the plane of the galaxy, the " $Z$ " components giving the smallest mean value. The absolute velocities tend to increase as the parallax diminishes, but the increase is more rapid for the small parallaxes, probably due to the greater insecurity of these measures. Hence in the final stage of the work stars having parallaxes less than $0.025^{\prime \prime}$ were excluded. It is concluded that the distribution of the absolute velocities for the remaining i 44 stars is approximately represented by an ellipsoid of revolution flattened in the plane of the Milky Way, and, unlike the proper motions or radial velocities, the absolute motions show no principal vertex.

The Solar Eclipse of April 17, I912.-We have received copies of two papers by Señor P. Carrasco, of the Madrid Observatory, reprinted from the Annals of the Physical and Chemical Society of Spain, dealing with the above eclipse. One of these papers (Ann., vol. xii., pp. 482-99, I9I4) gives a general description of the eclipse and of the work done at Cacabelos (Leon) by Señor Carrasco, who had charge of the spectroscopic work in the eclipse party under Señor Cos, organised by the Institute of Geography and Statistics. The central line of totality, it is estimated, passed about 2700 metres south-east from the position occupied at Cacabelos ( $3^{\circ} \mathbf{I}^{\prime} 39^{\prime \prime}$ W., Madrid, $42^{\circ} 35^{\prime} 53^{\prime \prime} \mathrm{N}$.). The observers saw something rather less than totality, but more than a mere partial phase. In the second paper (Ann., vol. xiii., pp. I8I-238, I915) the spectroscopic observations are discussed. The prismatic camera employed had "two (?) quartz prisms of $60^{\circ}$ angle, $48 \mathrm{~mm}$. in height, with an objective of $50 \mathrm{~mm}$. aperture and $630 \mathrm{~mm}$. f.l." Five exposures were made in ten seconds on one plate (Agfa), I $3 \times 18 \mathrm{~cm}$. Three of these spectra have been measured and reduced (Cornu-Hartmann formula, Rowland's solar wave-lengths, and Kayser's Hauplinien). The results are given in a table of some 2000 chromospheric lines between $\lambda \lambda_{3334}$ and 5897 . The ultraviolet region to $\lambda 3900$ has been mapped. The conclusions reached are in good accord with those now generally accepted; thus, although Fraunhofer lines are common to both spectra, yet the intensities are notably distinct, the larger chromospheric arcs agreeing better with the spark than the arc spectrum, and the principal lines of the high chromosphere correspond with the enhanced lines of Sir Norman Lockyer.

Anomalous Dispersion in the Sun.-Last year Prof. Julius, by a development of the theory of anomalous dispersion, concluded that there must be 
a mutual influence of closely neighbouring Fraunhofer lines. Early in the present year, however, Dr. St. John, discussing the same data employed by Julius, obtained a negative result. The matter is now carried a stage further in the June number of the Astrophysical Journal by Mr. Sebastian Albrecht. In this valuable paper a comparison is made of Rowland's solar wave-lengths of iron lines and the laboratory wave-lengths of the same lines to determine whether systematic differences are shown by lines having close companion and isolated lines. The paper hinges on a discussion of laboratory wave-lengths. All iron lines which have been classified according to pressure effect were examined, and consequently a chief feature of the paper is a complete list of Rowland's solar wave-lengths and corresponding international wave-lengths of these lines. International secondary standards were, of course, adopted without modification; for other lines a comparison was made between the sea-level determinations of Burns and the Pasadena-Mount Wilson values of St. John and Ware. A systematic difference so disclosed was ascribed to differences in the internal pressure of the arcs employed. The corrections to reduce the $I$. A. values to a pressure of $0.5 \mathrm{~atm}$. (the pressure of the solar reversing layer) were applied, and differences, Row., $\lambda$ I. $\AA$. 0.5 atm., as well as Row. $\lambda$ I.. I atm., were tabulated. Systematic differences between Rowland and the international system were eliminated subsequently by means of a curve. The following table concisely exhibits the principal results obtained :-

Means-Displacement according to Separation of Lines.

\begin{tabular}{|c|c|c|c|}
\hline & 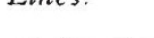 & Separation & \\
\hline & 0.0 to & $0^{\circ} 2$ to $0_{4} 4$ & $\begin{array}{l}0^{\circ} 4 \text { and } \\
\text { greater }\end{array}$ \\
\hline 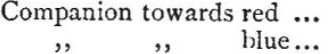 & $\begin{array}{l}+0.0103 \ldots \\
-0.0073 \ldots\end{array}$ & $\begin{array}{l}+0.0065 \ldots \\
-0.0024 \quad . .\end{array}$ & $\begin{array}{l}+0.0036 \\
-0.0010\end{array}$ \\
\hline
\end{tabular}

A Remarkable Group of Solar Spots.-The solar surface has recently displayed considerable activity, and possessors of telescopes have been much interested in the number and variety of spot groups almost continually visible. One large group which appeared during three, and possibly four, rotations forms the subject of an article by $M$. Camille Flammarion in the July number of 'L'Astronomie. An account is given of the solar activity during the spring months, and associated terrestrial, magnetical, and electrical disturbances.

A Catalogue of Star Clusters.--The star clusters shown on the Franklin-Adams chart plates have been catalogued by Mr. P. J. Melotte (Mem. Roy. Ast. Soc., vol 1x., part 5). The scale of the plates has been found excellently well adapted for the purpose, the open clusters not being dispersed by excessive magnification, whilst the scale is sufficient to show the features of globular clusters down to $3^{\prime}$ diameter. The catalogue contains 245 entries, and in addition to the usual co-ordinates (1900), galactic longitudes and latitudes of the various objects are also tabulated. The clusters have been classified according to degree of condensation in the following scheme of four classes:-(I) Globular clusters, condensed at centre; (2) loose clusters having regular well-defined outline; (3) loose clusters of irregular outline; (4) coarse clusters. By plotting with reference to Milky Way and classification it was found that practically all lie within $\pm 30^{\circ}$ of the galactic plane, whilst the globular clusters also tend to concentrate in a particular longitude rather more than half lying within $30^{\circ}$ of galactic longitude $325^{\circ}$.

$$
\text { NO. } 2392 \text {, VOL. 96] }
$$

\section{INDIGO IN INDIA.}

THAT the production of natural indigo in India is at present receiving the scientific attention which is its due must be welcome to many. The evidence that this is the case will be found in a Report on the Improvement of Indigo in Bihar, with Notes on Drainage and on Green-Manuring, by Mr. A. Howard, Imperial Economic Botanist at Pusa, and Mrs. Howard, published in IgI4 by the Bihar Planters' Association, and republished this year, with a second report by the same authors, on behalf of the Pusa Agricultural Research Institute.

The old belief that the source of the natural indigo of commerce is the species of Indigofera distinguished as I. tinctoria, though accepted by many chemists and some botanists in Europe down to the close of last century, was singularly incorrect. That the species in question does yield indigo is true; that at one time it was a main source of the dye is possible. It is, however, improbable that any appreciable amount of commercial indigo has been derived from I. tinctoria during the past hundred years.

When the intercourse between Europe and India which followed the discovery of the Cape route began, there were two main centres of indigo production and export. One of these was Surat, in Western India, where the plant employed was a form of Egyptian indigo, $I$. articulata, still the staple indigo plant in Eritrea, and still to be met with as a native crop in parts of Scinde, Rajputana, and the Deccan. The other was in Southern India, especially in Coromandel, and in Ceylon. The plant grown in this area differed much from Egyptian indigo. We may speak of it as Indian indigo, though with some reserve, because a plant from which indigo is obtained in Northern Nigeria cannot be distinguished from the Coromandel one, while a form closely related to it, which is wild in Nubia and the Eastern Sudan, has by some writers been believed to belong to this species. It is not inconceivable that the cultivated plant of Southern India may, like that of Scinde, have originally found its way east from Africa, and it is possible to imagine that on its way west from its original Nubian home to Nigeria, cultivation may have induced in it the same modifications as have taken place on its way east to Madras. The point which immediately interests us, however, is the fact that the name $I$. tinctoria, as originally employed, connotes the cultivated indigo of Coromandel.

European needs induced an extension of indigo cultivation. That of the Egyptian plant spread east from Scinde to the Panjab, and thence along the Gangetic Plain to the province of Bihar, in later times so closely associated with the manufacture of indigo. The cultivation of the Indian indigo spread to Malaya in the east, to the coasts of Madagascar, Zanzibar, and Socotra in the west; somehow, this indigo has even reached Northern Queensland. But neither plant extended to Bengal, or to Indo-China and China beyond Bengal. In Malaya the cultivation of Indian indigo went on along with that of a third plant, I. sumatrana, which we may speak of as Malayan indigo; this plant has found its way eastward to Formosa and, during the supremacy of the Dutch in Western India, was brought from Sumatra to Malabar, where it displaced both Indian indigo and yet another dye-yielding Indigofera. This fourth plant, I. longeracemosa, hardly deserves a commercial name, and only calls for mention because it has found its way to the Mascarenes and Zanzibar, and is preferred there to the other dye-yielding species.

This is not the place to discuss the policy which, early in the seventeenth century, laid an embargo on 